\title{
Sociocultural Sustainability of Small Tourism Enterprises: Observations from Ghalegaon's Community Based Homestays
}

\author{
Baikuntha Prasad Acharya* \\ Elizabeth Halpenny**
}

\begin{abstract}
Ghalegaon represents one of Nepal's most popular rural community based tourism entrepreneurship initiatives in a form of homestays. This paper explores the sociocultural sustainability of the Ghalegaon homestays. Fourteen individual interviews, five focus group discussions and onsite observations were used to discuss four categories of sociocultural dimension of sustainability: 1) inclusive, 2) collaborative, 3) resilient, and 4) modernizing. The findings revealed a slow impact of tourism with variations in perceptions of the local people. A critical insight to respective stakeholders are offered.
\end{abstract}

Keywords: Homestay, sociocultural sustainability, small tourism enterprise, Ghalegaon

\section{Introduction}

Homestay tourism has become a popular choice of many developing countries where tourism activities are considered to be important tools in achieving poverty reduction and sustained livelihood. In Nepal Himalaya, homestays that have emerged sporadically as an outcome of the Visit Nepal Year 1998 campaign have now been widespread across the nation with the homestay-priority programs of Nepal Tourism Year 2011. Given the country's under-resourced infrastructural investment in tourism development, the homestays have been a policy strategy for low-cost product development and entrepreneurship initiatives by capitalizing mainly on natural and cultural resources (Acharya \& Halpenny, 2013). Especially, the tourism policy documents and strategies such as Tourism Policy, 2008 and Vision 2020 have given significant emphasis on rural tourism development and promotions such as

\footnotetext{
* Baikuntha Prasad Acharya is a PhD Candidate, Faculty of Physical Education and Recreation University of Alberta, Edmonton, Canada. E-mail: baiku.acharya@ualberta.ca.

* Dr. Elizabeth Halpenny is an Associate Professor, Faculty of Physical Education \& Recreation University of Alberta, Edmonton, Canada.
} 
homestays. The annual programs of Ministry of Tourism and Civil Aviation (MoTCA) and Nepal Tourism Board include modest supports to the homestay initiatives.

While the homestay tourism is prioritized and practiced as a driver of tourism communities' sustainability, there is a lack of empirical studies of Nepali homestays. The purpose of this article is to identify social and cultural sustainability aspects of community based homestays and to offer a critical insight to the homestay operators, management committees and respective non/government authorities while contributing to homestay tourism scholarship. Sustainability is a contested notion discussed through different dimensions. This paper will conjointly highlight the social and cultural dimensions of sustainability thus referring to sociocultural sustainability. In this article, homestays are considered as a form of small tourism enterprise (STE) and their sociocultural sustainability is discussed. Nepal's Homestay Operations Procedures 2010 categorizes two types of homestay accommodations: 1) community based rural homestays, and 2) privately owned rural or urban homestays. This article focuses on the first type of homestay and presents the empirical evidence from key informant interviews, group discussions and observations derived from Ghalegaon, awell-recognized homestay destination in the western region of Nepal.

\section{Sustainability of Homestays}

\section{Homestays as small tourism enterprises (STEs)}

Homestays are typically alternative accommodation facilities for the tourists at affordable rates and with frequent opportunities to uniquely interact and immerse with the hosts and their lifestyle choices. Some popular other terms used for homestay in literature are 'home-based enterprise' commercial home enterprise' and 'commercial home' (Di Domenico \& Lynch, 2007; Lynch, 2005; McIntosh, Lynch, \& Sweeney, 2011). Kontogeorgopoulos, Churyen, and Duangsaen (2015) discussed the utilization of residential space of one's home for the purpose of homestay business as a commercializing process situating it at a middle ground between a friend or family member's intimate home settings and purely commercial environments in hotels or other conventional lodging facilities. While the homestays in Nepal are tourism products, this paper also considers them as STEs that are modestly workintensive, noncapital-intensive and are owned and operated by individuals and family and managed by a community based mechanism. Most community based Nepali homestays fall under the STE category described in Nepal's Industrial Enterprises Act 2049[1992] that a small business is an enterprise that has a fixed asset up to NRs30,000000 (approximately USD 300,000).

Homestays share the characteristics of small enterprises, namely, low or no number of employees, informal organization structure, small market share, small annual revenue and turnover, and limited infrastructure and assets (Churhil \& 
Lewis, 1983). Like other small tourism enterprises, homestays are run part-time, full time or home-based by offering services and products (Getz, Carlsen, \& Morrison, 2004). Homestays in Ghalegaon have independent owners/operators who supply the required capital to their enterprises (Scott \& Bruce, 1987) and are managed by a community partnership system which relies on social relations of the community members and their networks (Ahmad, Abdurahman, Alik, Khedif,\& Bohari, 2014; Peredo \& Chrisman, 2006) to support social and economic development of residents (Kimbu \& Ngoasong, 2016). Ghalegaon's homestays are operated locally and the owners/managers are in one home community under a community based homestay management committee. Such community based homestays, owing to their operational purpose to seize both economic and social goals simultaneously, are also defined as social entrepreneurships (e.g., Acharya \& Halpenny, 2013;Kimbu \& Ngoasong, 2016; von der Weppen \& Cochrane, 2012).

\section{Sustainability of Homestay STEs}

Sustainability is an approach of stewardship where wellbeing is maintained over a long period by bequeathing resources, quality of the environment, and capital to future generations (Kuhlman \& Farrington, 2010). Many dimensions of sustainability are discussed by different authors, of which a three-pillar tradition is a popular approach in tourism studies that includes economy, society and environment. The UNsponsored World Commission of Environment and Development (WCED) report, Our Common Future provided a futuristic viewpoint of sustainability based on these pillars advocating for minimum negative impacts on these pillars with a balanced reconciliation of human production and consumption (WCED, 1987). Along with these three, some other dimensions such as cultural, political and technological are also considered in some studies (e.g., Choi \& Sirakaya, 2006; Gibson, Hassan, Holtz, Tansey, \& Whitelaw, 2013; Park \& Yoon, 2011). A few other dimensions such as democratic governance, continued wellbeing along with management systems, service quality, facility, and outcome of facility and services are also used in tourism studies to discuss sustainability (e.g, Kuhlman \& Farrington, 2010; Robert \& Tribe, 2008).This paper will focus on social and cultural dimensions only and present them conjointly to evaluate the sustainability of the Homestay STEs in Ghalegaon.

In most tourist destinations, small businesses are the primary providers of services to tourists and hence are considered the economic lifeblood of tourism sector (Thomas, Shaw, \& Page, 2011). The Nepali government has assigned high priority to the small enterprises, specifically those that are rural and community based (MoTCA 2008). The government is seeking premier tourism destination status for Nepal by promoting rural areas, and thereby has encouraged local entrepreneurs to venture into tourism businesses such as homestays (MoTCA, 2008; MoTCA, 2009; MoTCA, 2010). As a result, innumerable homestays have opened across the country 
with many of them in rural communities and with host peoples' ardent desires for tourism-induced growth and development. Observations of such homestays across the country have indicated different experiences. In a personal interview, a tourism policy maker with the MoTCA, agreed that many of the host-communities' excitements are fading away as they are struggling to survive while some others are prospering. Sustainability of the homestay STEs is generally a neglected area of study in tourism scholarship. Our attempts to explore previous empirical studies of the STEs' sustainability in Nepal yielded no significant literature except for some annual enterprise reports (e.g., NRB, 2015) and limited empirical studies on Nepali homestays (e.g. Acharya \& Halpenny, 2013; Regmi \& Walter, 2016). Tourism literature related to pro-poor tourism, sustainable tourism and community/community-based tourism documents the salience of STEs and how they contribute to development in a consistent and incremental manner. These studies outline the nature of the STEs and make many assumptions about the sustainability of such businesses. This paper argues that such assumptions are often overstated and are rarely observed in the reality of less-developed countries' contexts. Nevertheless, academic research on small tourism enterprises has developed slowly, and calls for research in this area have been issued (Thomas et al., 2011).This article intends to contribute to this deficit of knowledge by studying the case of Ghalegaon Homestays in Nepal.

\section{Sociocultural sustainability of homestays}

Socio-cultural sustainability incorporates social and cultural values. Some of social issues like welfare, safety, healthy environment, access to education, opportunities to learn, identity, sense of place, and public participation are described under social values in the Agenda 21 by the Earth Summit (UN, 1992). Later, Culture 21, the cultural working group under Rio+20, recommended culture as the 4th pillar of sustainable development as an amendment to the Agenda 21 and described capabilities such as literacy, creativity, critical knowledge, sense of place, empathy, trust, risk, respect, recognition as cultural components of sustainability (UN, 2012). Additionally, a contemporary outlook of cultural components consists of values of cultural heritage and spaces in terms of practices, representations, expressions, knowledge, skills, and instruments, objects, artefacts, tradition, identity, diversity, spirituality, and esthetics (Axelsson et al., 2013). Magis (2010) considered change as a constant force in society and argued community resilience, which can be developed by actively building and engaging the local capacity to thrive in changed environment, as an important indicator of social sustainability.

Social entrepreneurships such as homestays are recognized in terms of poverty alleviation that they enable the poorest and underprivileged households to prosper (Kimbu \& Ngoasong, 2016; Von der Weppen \& Cochrane, 2012). Kimbu and Ngoasong (2016) highlighted women and their small tourism firms as social bricoleurs and/ 
or social constructionists that they act on local opportunities with local resources to offer improvised solutions to locals thus simultaneously combining their social transformational and commercial goals. Acharya and Halpenny (2013) explored social transformations of women homestay operators from housewives to managers of the enterprises and bread winners of the family; these women have also earned their spaces in social and community affairs by slowly overcoming the limitations imposed by male-dominated settings. Through their tourism activities and services in a community, homestays can instigate social changes towards modernizing the communities' life style through host-guest interactions (Harrison, 1992; Sebastian \& Rajagopalan, 2009; Sharpley, 1994), create opportunities for women and minorities for their independence and empowerment (Acharya and Halpenny, 2013; Kauppila, Saarinen, \& Leinonen, 2009; Urry, 1991), bring communities together for entrepreneurial efforts (Peredo \& Chrisman, 2006), conserve traditional values, community pride, and promote quality of life (Ahn, Lee, \& Shafer, 2002; Azam\& Sarker,2011; Sarinnen, 2006).

Based on the salience of above discussions, four broad categories of sociocultural sustainability were decided for this study: 1) Inclusive (e.g., class/castes, gender, culture), 2) Collaborative, 3) Resilient (e.g., adaptability, integrity and strong domestic supply chain), and 4) Modernizing (e.g., host-guest relationships, advanced health and education system). Three different consultations with nation's key tourism personnel in Kathmandu verified these categories defined for this study.

\section{Methods}

\section{Data Collection}

A case study approach (Creswell, 2007; Merriam, 2009; Simons, 2009; Stake, 2005; Yin, 2014) was chosen as a methodology with interviews, focus groups, observations and secondary sources as methods of data collection. The data was collected during October 2014 to February 2015 by the lead author in Ghalegaon, the case study site. Three different trips were made with at least a week's on-site stay for each visit. The second and third visits were used to understand any changed contexts in the destination and the third visit was also utilized to conduct memberchecks with the participants. Prior to the field trips, three in-depth interviews were conducted in Kathmandu to understand the sociocultural issues of small tourism businesses' sustainability at the context. Their views were also solicited to confirm the integrated four categories developed for the sociocultural dimensions of homestays' sustainability in this study. The participants comprised of a high ranking official/expert from MoTCA, an established trekking businessman cum executive of Trekking Agency's Association of Nepal, and a professor of (tourism) entrepreneurship at Tribhuvan University. 
Eleven interviewees were purposively selected with the help of mediators and with a snowballing approach to conduct the interviews at the study site. Use of mediators as gate keepers helped the researcher access local participants and key informants (Patton, 2002). Of the eleven participants, five in-depth interviews were conducted with the representatives of: a local tourism management committee $(n=1)$, a local protected area authority $(n=1)$, homestay owners $(n=1)$, local non-elite residents $(\mathrm{n}=2)$. These interviews lasted from 45 minutes to 90 minutes. With remaining six interviewees, semi-structured interviews were conducted; the participants were: homestay owners/operators $(n=4)$ and local Dalits $(n=2)$. These interviews lasted from 30 minutes to 45 minutes. Among the interview participants, six were females and five were males. All interviews were conducted at the participants' work/home places. The variation in interview times occurred due to the participants' interest, knowledge and interactive nature.

Five focus group discussions were additionally conducted on-site to enable people consider their own views in milieu of others' views (Patton, 2002). The participants of the focus groups conversed among themselves, questioning, challenging and answering one another. A total 37 people participated in the focus group discussions ranging from minimum 5 to maximum 12 members in each discussion session. The five focus groups consisted of five different cohorts of people with similar lived experiences: long term residents $(n=7)$; local institutions such as youth clubs, etc. $(n=5)$; women's group representatives $(n=12)$; minority castes - Dalits $(n=8)$; and, local officials $(n=5)$. Three of these discussions were conducted at the local community hall and two of them at the office of the local homestay management committee. These discussions lasted 75-90 minutes. Apart from women's group members, two participants each from the youth club and minority caste were females $(n=16)$; all others were male $(n=21)$.

The interview and group discussion participants' education level was diverse illiterate to well-educated. They were all minimum of 18 years of age. No personal information of the participants and local people were collected. Due to the nature of this data collection process in focus group discussions, anonymity was not possible; however, the collected data was treated in a confidential manner.

On-site observations mainly focused on: physical setting; the participants and their behaviors; activities and programs; and some subtle behaviors such as symbolic and connotative meanings of words, nonverbal communication and unplanned activities (Merriam, 2009; Patton, 2002). An extensive field diary was maintained using an observational protocol (Creswell, 2007). The observations informed the data analysis.

Some other literature consulted during the study were: the periodic surveys and studies done on the local/regional/national levels related to household income, 
education, health, employment rate, visitors' arrival rates, conservation area entry fees, tourism revenues, and tourism statistics, etc.

For data analysis, the field notes and transcripts were coded, categorized and themed to ease the process of establishing patterns and overarching themes (Braun \& Clarke, 2006; Charmaz, 2006).

\section{Study sites}

Ghalegaon is chosen for this study because it is a popular rural homestay destination mainly for domestic tourists and is also considered by Nepali tourism authorities as exemplar of successful rural tourism community.

Ghalegaon is a clustered settlement of the Ghales, Gurungs (two indigenous castes) and Dalits (the minority caste) in Uttarkanya village development committee (VDC) inside the Annapurna Conservation Area (ACA) in Lamjung district of western Nepal. Hamlet of Ghalegaon comprises 1, 2 and 3 Wards (the smallest unit of the VDC) of the VDC with 111 households. The entire VDC has a total 281 households with a population of 1574 (CBS, 2011). Ghalegaon is one of the pioneers in homestay tourism in Nepal. The Ghalegoanese teamed up for a homestay initiation in 2001 and collaborated with local and regional tourism agencies to establish the community as a homestay destination. Ghalegaon's main attractions for tourists are opportunities to enjoy a homestay while experiencing spectacular views of mountains and traditions and lifestyles of Ghales and Gurungs. Out of 111 households, there were 28 registered homestays at the time of data collection with a capacity of approximately 100 beds per night under a communitybased body named as Ghalegaon Tourism Development Subcommittee (GTDS). Four other homestays were in process of registration. The GTDS is a local mechanism that manages homestay tourism, complying with the conservation area's guidelines and norms. A total of 23,500 visitations were recorded in Ghalegaon in 2014 as per the GTDS' record. Homestays in Nepal are registered with the MoTCA upon fulfilling criteria outlined in Homestay Operations Procedures 2010.

\section{Findings and Discussions}

In rural communities with tourism potential, small-scale tourismentrepreneurship such as homestays are encouraged in a community-based model to achieve integrated economic, social and environmental development in a participatory bottom-up approach. The community based tourism enterprises avail opportunities of collaborative engagement of the local people to promote their communitarian structures with commercial system. It provides an alternative to pro-agrarian livelihoods. Nepal government has been prioritizing a pro-poor approach of tourism development by considering small tourism businesses such as homestays to be effective tools to contributing to poverty alleviation in rural destinations (MoTCA, 2008). 
Many studies have explained that the modern urban tourists including the Western visitors are interested in the distinct ways of lives and cultures in rural landscape and they aspire to explore the unexplored, exotic and distant communities (Brown \& Hall, 2008; George, Mair, \& Reid, 2009). The uses and/or consumptions patterns of local resources in tourism explain the overall impacts which discern whether the destination community is sustainable. Although the host-guest trade-offs can positively bring socio-cultural changes to traditional societies by demonstrating "modern" ways of life (Scheyvens, 2011), the modernization impacts on sociocultural and environmental fabrics of destinations can be non-positive and can increase the dependency of peripheral communities on city centers and urban areas. This paper aims to contribute to this discourse and literature by bringing the findings from Ghalegaon that highlight the homestays' utilization of social and cultural resources and the resultant impacts on local community. Sociocultural sustainability observations are discussed next.

\section{Inclusive}

Community people in Ghalegaon are both geographically and emotionally close; they are driven by common interests, values and strong social cohesion (Acharya \& Halpenny, 2013) because they have inherited a common system of culture and lifestyle choices. Ideally, in community-based enterprising contexts, many domains of potential deprivation that create exclusion are subdued and different ways that promote inclusion are encouraged. Sloan, Legrand, and Simons-Kaufmann (2014) showed social progressions such as improved quality of life, increased income capacities, poverty decline, and better education of indigenous communities by community based hospitality projects' social inclusive approaches. Ghalegaon homestay is a community-based initiative in a remote mountain hill top with shared quality of life objectives. As confirmed by one of the interviewees who is a local politician, homestay owner and played a major role for homestay initiative "this [homestay] has emerged based on goals of community's overall wellbeing by bringing the community members towards an equitable benefit sharing system". Inclusion, in this paper, focuses on involvements of gender, caste and class differences of Ghalegaon community members in homestay operations and tourism benefits sharing.

Typically, the GTDS employees arrange the accommodations of the visitors on rotation basis to keep homestay allocations proportional and equitable. One of the interviewees, an employee at the GTDS, noted that they sometimes consider the visitors' special requirements and available facility's quality match while assigning the guests to accommodation facilities but without impacting the fair distribution system. When visitors overflow to the capacity of the existing homestay beds, other non-homestay registrants also receive the guests at their households; the GTDS employees coordinate this. According to the GTDS representative, accommodating 
the spill-over visitors, supplying consumable products such as vegetable, chicken, local alcohol, etc. to the homestay operators, and contributing to the cultural shows are the opportunities where all the villagers share the direct benefits of tourism. Later, two other homestay owners also confirmed what the GTDS employee stated but reported that most homestay owners can supply their own farm-products except for local chicken and liquor that they may need to buy occasionally from other community members. There were a couple families who would primarily brew local liquor for this purpose. The two homestay owners and the GTDS employee agreed that the tourism system has not discriminated the Dalits - the Bishwokarmas - and the women in Ghalegaon that they are also equitably involved in benefits sharing.

Surprisingly, interviews with a single-woman homestay operator, a non-elite Gurung woman, and a Dalit male revealed many irreconcilable information to what has been provided by the earlier interviewees. The single-woman homestay operator reported that she was often discriminated against in terms of receiving the guests. According to her, the GTDS perceived her sociocultural boundaries based on her widow status as a limitation for fulfilling many of the logistics arrangements and errands associated with hosting guests. The non-elite Gurung woman interviewee showed her perception of unimportance of tourism to her by quoting an adage kaaglai bael pakyo harsha na bismat' [ripe aegle marmelos gives neither pleasure nor displeasure for a crow] and further resented that her family had received no tourism-induced benefits, which are enjoyed by the rich locals. These views are further supported by a Dalit interviewee's insight that he might have sold less than a dozen chickens and no more than 50 liters of alcohol across his entire life-time to the homestay owners. His agitation was noticeable when he further stated, "these [liquor and chickens] are touchable and they [the homestay operators] use when they need, and we make their furniture and tools and that are also usable, but why are we so untouchable that we cannot have our own homestays?" Participants at a group discussion with the minority caste reflected similar tones that they were discriminated against. Another interviewee, an octogenarian Ghale who was once an active homestay owner in the early years, hinted gradual incremental changes in terms of social and cultural inclusions of the minority castes and the women in the society. This participant explained that the inveterate caste system still exists in the community but both Dalits and non-Dalits have exhibited respect to each other's norms. He said, "non-Dalits still expect the Dalits to not enter into their houses, and the Dalits respect the norm by abstaining from entering". This respondent further remarked about the caste-sensitivity amongst the guests to Ghalegaon homestays that the non-Dalit middle and high class Nepalis, the main market source from across the country, would not prefer to stay overnight at a Dalit's place. This latter opinion was largely confirmed during the group discussions of senior citizens, local officials and local institutions' representatives, whereas the 
group discussions with the women and minority caste reflected variations. The women participants of the group discussion reported their additional load of work to their regular chores due to homestay operations for piecemeal benefits and no increase in empowerment within the family unit. One of the participants hinted women's overutilization saying: 'after a strenuous day we old women still have to 'move our waists' [dance] at the cultural shows until midnight and then get up early in the following morning to begin the same cycle again". The Bishwokarmas at the minority caste group discussions complained about Ghale/Gurung hegemony in tourism business ownership and reported bein discriminated by not being able to run a homestay; one participant exclaimed: "they [Ghale/Gurung] include our man [a Dalit] in the tourism committee but they do not let us run a hotel [homestay]; they just show off". A Dalit senior citizen from the same group discussion identified a handful of local elites whose permissions are necessary for the Dalits to engage in Homestay enterprising.

While there are variations in the perceptions about operations of homestays depending on the gender, class and sociocultural identity of the participants, it is noteworthy that the rural Nepali communities such as Ghalegaonese are aware of their social and political rights and responsibilities. The roles defined by erstwhile caste system, male dominated norms and elite monopolized economy are gradually waning. Due to lifestyle values that were emerged according to influence of traditional power dynamics based on gender, class, caste and wealth in most such societies, opportunities are less likely to be retrieved equally by all in the short term, even under regulations based on social justice. Font, Garay, and Jones (2016) discussed the influence of traditional values in lifestyle choices and their impacts on sustainability behaviors of small tourism enterprises inside the protected areas. The mindset of the domestic homestay-actors reflects a caste-sensitive Nepali society at all levels. However, a recent update from Ghalegaon that a couple of Dalit households have started homestays represents a milestone in local social inclusion processes. It also appears to be a trial run for the Nepali society in general. Observations during the field trips have found that the women in Ghalegaon were overly busy, but it was also noticed that most males were actively assisting them. All homestays were run by family members and no external employees were hired thus it dismisses the issue of inclusive employment opportunities. However, the age-based distribution of work is uneven at these homestays that mostly older adults (60yrs+), with no young members in their family to assist them, are operating the businesses. It mirrors the contemporary situation of most Nepali rural communities that the youth members are away from their homes to work in overseas in labor markets. At the time when the nation is in process of implementing a new constitution that is reported to be inclusive, the evidence from this study of homestay entrepreneurship in Ghalegaon suggests some progress, but also remnant forms of discrimination. 


\section{Collaborative}

Despite differences in definitions of community based enterprises across the countries and communities, the majority of discussions in the community tourism literature include participation and partnership as integral collaborative characteristics of community based tourism. Many best practices show a fostered collaboration and institutional linkages of the community members and stakeholders groups during exploration, planning, developing and managing of tourism initiatives (Jamal \& Getz, 1995; Parker, 1999; Simmons, 1994). Some studies (e.g., Moswete, Thapa, \& Child, 2012; Tosun, 199; Yang, Wall,\& Smith, 2008) have highlighted pseudo local participations due to deficiency of knowledge and skill, funding agency imposed communications and collaborations modality and over interventions of external donor agencies including government bodies. In this study, the Ghalegaon homestays' collaborative efforts with the community members and external stakeholders were explored. The discussions below explore harmony, engagement, partnership and networking as key features of sociocultural collaborations as seen among homestays in Ghalegaon.

Most group discussions indicated a well-maintained local collaborative system that the community members and small local institutions were regularly consulted and engaged in decision makings about tourism development and homestay management initiatives. This affirmed what a GTDS employee and a homestay owner and executive board member of GTDS had also claimed and emphasized. No participants raised any other negative issue pertaining to uses of local cultural heritages in tourism offerings except for a concern about the influence of modernization and the challenges of keeping cultural authenticity intact. Interviews with the Dalit participants and the discussion with the Dalit group complained that their representations in collaborative processes were insignificant and have remained ineffective. A Dalit participant said: "our representations in the committee and its meetings are just to fulfill the legal requirements of country's reservation system because they [the non-Dalits] do not listen to us; we are just ciphers". Another Dalit, who is also a local school teacher, expressed a different perspective by elaborating on the supposedly ineffective involvement of Dalits in community collaboration:

Due to limitations and restrictions of past ill-practices, members of our caste are less aware and educated than the Ghales/Gurungs and only a few of us have exposures to outer world; this is what is making us less contributing to social affairs. (BA, February 2015).

This participant later explained some examples of slowly decreasing traditional caste-based malpractices. The group discussion with the women group highlighted the roles of women as the most effective in the tourism system. A similar view was held 
by the local youth club members that they have been instrumental to help organize the bi-annual Ghalegaon Mahotsav [Ghalegaon Festival] to the GTDS. The group discussion with local officials comprising representatives of public school, health post and village development committee affirmed their observations and experiences of effective collaborations within the community members, their respective institutions and the GTDS. The interview with Annapurna Conservation Area's local unit representative highlighted the significant roles of the ACA's project office to overall development of the community. Most interviewees and the participants of group discussions showed less knowledge about the partnership between the local tourism management and external stakeholders at the regional and national levels. The GTDS employee and executive member reported a few calendar-based partnership and sponsorship opportunities offered to them by the district development committee, district chamber of commerce and industry and the regional tourist board such as re-printing information brochures, conducting occasional basic homestay operation trainings and providing a nominal fund to organize the Ghalegaon festival.

However, above discussions reflect an increased level of local engagement and partnership of Ghalegaon homestay, given the twenty years of this venture in the nation's most popular homestay, the collaborative strength of Ghalegaon homestay could have reached to a different height by now. While the local level collaborations appeared to boost social reformations and cultural conservation, the partnerships with external agencies have remained underdeveloped. For example, the nation's tourist board is supporting the GTDS in a very stereotypical fashion by re-publishing an information brochure annually, providing occasional basic cooking/baking trainings and dispersing a nominal funding for the local bi-annual festival. Efforts towards market-based creativity are imperative for any destination development and promotion campaign in the competitive rural tourism market place which has not yet been effectively reflected in the partnership efforts of the tourist board and other immediate tourism agencies.

\section{Resilient}

Definition of resilience rests on complex adaptive systems theory that it is a notion of maintaining equilibriums of different kinds such as engineering, sociological and ecological, etc. to deal with the future uncertainties (Davoudi et al., 2012; Folke et al., 2010; Holling, 2010). A community's resilience is often looked at through its ability to maintain, renew, reorganize social and cultural system functions (Varghese, Krogman, Beckley,\& Nadeau, 2006). Franklin, Newton, and McEntee (2011) further discussed community resilience as both process and outcome that a resilient community is empowered to take control of their own developmental efforts and achieve an accelerated adaptive capacity. The concept of resilience in tourism has mostly focused on economic resilience than on social and cultural or other forms 
(Lew, 2014). Farrell and Twing-Ward (2004) suggested enhancement of resilience as an adaptive management approach rather than trying to manage tourism through attempting to maintain equilibrium in the constantly changing and evolving world and its disturbances. Hopkins and Becken (2014) highlighted effects of evolving processes of people and institutions on host communities, cultures and tourists and discussed the degree to which the population can cope with the adverse effects of tourism in terms of resilience.

Resources of sociocultural capitals such as knowledge and belief systems, traditions, customs and rituals and roles of family members and gender and ethnic identity are the influencing factors to Ghalegaon homestays' local supply chain. These factors also affect the homestay enterprises' continuance. In this paper, concept of resilience focuses on how Ghalegaon homestays have been addressing social and cultural changes such as patterns of change in using social and cultural capitals and resultant changes in lifestyle choices to continue their homestay enterprises.

Most interviewees described a topsy-turvy experience of tourism development processes in Ghalegaon and referred to ongoing political instability and transitions in the country as the reason for the tourism volatility. The Maoist insurgency during 1996-2006 was reported as the worst tourism time in Nepali tourism, and the years following signing of the Comprehensive Peace Accord on 21 November 2006 have been advantageous years for tourism development. The executive member of GTDS who is also an owner of a homestay emphasized Ghalegaon communities' sense of place ownership, perseverance, agility and local resourcefulness as keys to cope with hard times. He was proud of how they have become able to keep intact their cultural heritages while still bringing gradual reforms in social practices and lifestyles. $\mathrm{He}$ said:

While many parts of the country are under ethnicity conflicts and relationship tensions, here in Ghalegaon we have no problem of that kind because we do not want to lose our nationwide fame; we are recognized across the country due to tourism and how rich we are in cultural and natural attractions. (GPB, February, 2015).

Most participants of interviews and group discussions agreed on the community's strength of a robust local supply chain built on social and cultural capitals. However, they highlighted a common concern of possible succession crisis of homestays due to lack of young people engaged in the businesses. Discussion with local institution members, who were all from a local youth club, agreed that the issue of youth relocation (temporary and permanent) from the village to elsewhere was problematic. This group said that the tourism could be more competitively done than typically if there were enough youth and there would be no concern for continuing the entrepreneurship. 
The youth group critiqued community members' sluggish adaptability and showed their concern about engrained routines of serving food and showing cultures to the guests by the homestays. Interestingly, a non-elite interviewee showed a concern of deteriorating sense of respect of youth and teens towards local traditions mentioning some of their discourteous demeanors such as smoking marijuana and swearing and imitating non-local cultures.

Above discussions revealed some important aspects of Ghalegaon's resilience. As explained by the members of different group discussions, Ghalegaon homestays could thrive on group travels from school, college and university students and nearby city dwellers at the times when Nepal experienced a huge decline in national and international tourists' arrival. Overcoming the insurgency times and prevailing the homestays epitomize Ghalegaon's resilience. The utilization of social and cultural capitals over time in homestays appears neither impacting Ghalegaon's typicality much nor they are commoditized sophisticatedly and commercially. This inert adaptive process of Ghalegaon homestay on the one hand exhibits its resilience by being able to safeguard and keep intact the local sociocultural resource bases. On the other hand, it reflects a slow process of local development on the aspects such as institutionalizing homestay enterprises, infrastructural advancement, and capacity building and strengthening social bonding of local communities over two decades (Holladay \& Powell, 2013). The GTDS should build a good and innovative relationship with tourism stakeholders and assist the community to empower its flexibility to rebound and reorganize when challenges come to maintain the continuity of the homestays (Amir, Ghapar, Jamal, \& Ahmad, 2015). A pressing issue is succession of homestay management in future; this is shored with other sectors in Nepal who experience a shortage of youth employees and entrepreneurs. The relocation of youth overseas for foreign employment is a national challenge.

\section{Modernizing}

Along the development processes and through host-guest interactions (Smith, 1989) tourism promotes modern values, social progress and cultural evolution (Liu, 2003). Telfer (2002) highlighted social transformations in rural destinations by indicating declining values of family and other collectiveness and introducing of modern values and institutions similar to Western societies. In rural tourism contexts, there is an ongoing debate and tension between modernization and development processes and traditionalism. The consumers of rural tourism such as in Ghalegaon homestays are the seekers of exotic and primitive experiences that characterize authentic traditional lifestyles and cultural values of local people, whereas modernizing processes in contrast is an evolution from a traditional society to a modern society through socio-economic development strategies (Schmidt, 1989). While access to better quality health, education and communication services than in the past is a 
basic general transformation of modernization in most rural communities, tourism, in addition, promotes modern values, social progress and cultural evolution (Liu, 2003). As such, a possible change in cultural integrity is difficult to reject. This paper reports Ghalegaon homestays' observations on how the modernizing affects and traditional values are maintained and sustained.

The group discussion with Ghalegaon's long-term residents brought out their lived experiences with many gradual developmental changes in the villages such as upgrading of local school, construction of road, access to clean running water and introduction of telephone, cable television, mobile phone, etc. Access to nearby cities, country's capital and overseas for multiple career opportunities of local youths were also reported as a change by this group and other interviewees. A teacher participant who is from elsewhere but has been residing in the community for almost a decade elaborated improved social and political awareness of the locals. Most these changes were explained as a normal outcome of overall development processes, rather than a tourism-specific. However, they considered the role of tourism as positive toward such changes. The homestay owners accounted modernizing of their everyday lifestyle choices including food habits, clothing and home decoration patterns due to operating the homestays. A Dalit uneducated woman interviewee shared her tourisminfluenced feeling and also attested what the teacher has outlined about improved awareness by saying: “...now people from outside come and walk around in the village, it is a shame if we keep our yards unclean and let our kids defecate in opens or leave them untidy and uneducated." Most participants' views were similar about overall development processes in the community that a slow and steady positive change was occurring and homestays have somehow contributed to it. However, divergent perceptions were reported on the utilization of traditional heritages by homestays and the impacts thereon. All homestay owners, the executive committee members and the GTDS employee mentioned that the community's sociocultural attributes were carefully used as tourism attractions and were not harmed. These participants claimed that by using local features in tourism they have rather promoted their identity to the outer world and helped strengthen the community's image. Other participants, however, raised concerns regarding the ways the cultural heritages were used; they complained about the cultural shows' fusion with external popular cultures. A participant in the women's group discussion who is also a member in local cultural shows mentioned her dissatisfaction about dressing-up saying, "we (women) completely garb in our ancient attire but the males wear jeans and shirts and wrap around by only Bhangra [the Gurung dress] and co-perform". A local non-elite interviewee commented that some of their unique cultural heritages such as Ghatu and Krishnacharitra which would be performed rarely only during certain auspicious occasions are now haphazardly performed for commercial purposes. The employee 
of the GTDS confirmed the random use of such unique heritages in tourism, however he justified that tourism has been instrumental for all developmental changes because such products have been enticing national policy makers, planners and politicians to visit Ghalegaon thus creating a platform to grow relationships with them.

Many aspects of gradual progression and a modernizing tendency of Ghalegaon can be realized in above discussions. The tardy development course therein simply portrays national tendency of overall development process. The discrepancy between perceptions on uses of cultural heritages in Ghalegaon tourism exemplifies the ongoing discourse of modernization versus traditionalism and/or authenticity versus commoditization in rural tourism literature. A clear distinction of perception between the tourism related and non-related locals is also noticed in that the homestay owners and the members associated with GTDS were considering tourism as a promotor of their sociocultural richness whereas others were critical. Finding perceived differences is normal, and parallels the many tourism studies that argue residents' positive and/ or negative perceptions are determined based on the social exchange defined by cost-benefit analysis and tourism-induced impacts (Byrd, Bosley, \& Dronberger, 2009; Choi \& Murray, 2010; Gursoy, Jurowski, \& Uysal, 2002; Nunkoo \& Gursoy, 2012; Perdue, Long, \& Allen, 1990). However, the case of Ghalegaon reasserts the importance of how rural tourism should be developed and modernized but offer traditional experiences to the visitors.

Mbaiwa (2011) explored declined traditional livelihood activities replaced by modern cash economy of a rural community in Botswana caused by tourism development. The study however also highlighted a sense of insecurity of tourisminduced livelihood and lifestyle transformations among the community members (Mbaiwa, 2011). Liu (2003) argued it unfair to keep the less developed world its traditional culture for the sake of the tourists who wish to seek exotic and primitive experiences. In the case of Ghalegaon, where tourism appears to offer socioeconomic opportunities and remains auxiliary to many positive changes, commoditizing of the sociocultural features without eroding their original indigenous meanings and essences could be a wise strategy. To operationalize this innovatively and effectively, the GTDS has to use the indigenous knowledge and input and professional marketbased strategies in close collaboration with key tourism agencies.

\section{Conclusion}

This paper discussed Ghalegaon homestays' sustainability by focusing on how the homestays have utilized and impacted social and cultural aspects of the local communities. Because the homestays are community based enterprises aiming to contribute to communities' wellbeing, how these businesses have kept abreast of this goal while mostly relying on local sociocultural resources was shown. The four 
categories of sociocultural sustainability showed some positive shifts in sociocultural aspects of the traditional rural village. Homestay tourism was generally reported as a key catalyst for Ghalegaon's overall development. Particularly, increased sense of cultural identity, diminishing caste-based practices, empowered women's state and enhanced local supply-base appear to be promoted by homestay enterprise. A gradual and steady shift of Ghalegaon's traditional lifestyle patterns to modern lifestyle choices illustrated achievements towards improved livelihood, poverty reduction and rural rejuvenation through tourism entrepreneurship (Harrison \& Schipani, 2007; Harris, 2009; UNWTO, 2012).

Ghalegaon homestays were observed to have maintained no written record of daily incomes, expenditures and guest numbers and demographics, etc. They were confused about the succession management of homestays for future. Their perplexity was also apparent towards partnership and engagement with tourism stakeholders and they did not have formal plan about marketing and promotion of their destination and developing a reliable market-base. Arguably, individual local entrepreneurs and a community based management system such as of GTDS may possess strong understanding of local phenomena and can operate, act and adapt according to contemporary market situations and they may not necessarily need to have good grasp of theory of business sustainability (Robert \& Tribe, 2008). Rural STEs are small in size and are easy to conceptualize, operationalize and then to strategically manage with commitments of a core team (Man, Lau, \& Chan, 2002). They are flexible in financial, operational, strategic and structural aspects that help make such enterprises sustainable. While this notion is true of the supply side of rural enterprises management, its demand side has a complicated scope that the market for such business is broad and non-local (Scott \& Bruce, 1987) and that the tourism offerings are developed commoditizing and negotiating with the local supply chain - natural and cultural resources. Also, lack of formal relations and communications of GTDS with regional and national level tourism associations appear to hinder their resilience when new competitive destinations emerge and interests of market change. Rural destinations such as Ghalegaon are largely dependent on internal tourism market dynamics that are determined by larger tourism enterprises in Kathmandu and Pokhara, and more formal relations and communications with such stakeholders are necessary to build a strong market-base (Murillo and Lozano, 2006; Russo and Tencati, 2009).

Lack of expertise, resources and innovation and less knowledge of market requirements and opportunities are other challenges of most rural tourism operators which can be improved by collaborating with other stakeholders. Innovations in product, process, enterprises operation and marketing are the opportunities for Ghalegaon to achieve through partnering with external collaborators. RuizBallesteros and Herna'ndez-Ramı'rez (2010) highlighted an empowered state of 
marketing, commodification, objectification and appropriation of tourism products through collaborations with stakeholders. Using the collaborative approach, the trainings and skills development endeavors can be tailored focusing innovative and engaging educational practices to facilitate sustainability practices in Ghalegaon homestays (Condon, 2004).

The idea of community based homestays in general seems a top-down injection of development hopes in Nepali villages; this was largely agreed by the three key tourism personnel consulted in this study. They also confirmed some of the examples of Nepali homestays that have struggled to survive or collapsed after a temporary eminence due to inadequate infrastructure, insufficient economic resources, and less skilled tourism personnel. Lack of sustainable partnerships with government and other stakeholders and shortage of innovative programs for Ghalegaon homestays' promotions reveal the nation's tourism promotion body's stereotypical marketing tools and homogeneous products development approach. Ineffective tourism authorities muddled in corruption and dysfunctional administration of Nepal appear to be exacerbating these issues rather than addressing them. This paper argues that sustainability of the communities is possible only if the small tourism businesses, the basal component of rural tourism initiatives, are sustainable. Looking at the nation's homestay champion's (i.e. Ghalegaon's) story, it is argued that such initiatives should be taken with a long-term bottom-up plan than haphazardly. Entrepreneurship innovations that are designed based on local resources of Ghalegaon and policies that are centered to the communities' social welfare will boost up social inclusion processes also (Hall, Matos, Sheehan, \& Silvestre, 2012). Further studies that cover different types of small tourism enterprises (e.g., lodges, guest houses, restaurants, cafes, gift shops, tea houses, etc.) consisting of community based and privately owned homestays from different parts of the nation including other dimensions of sustainability are recommended to validate the findings of this study.

\section{Acknowledgements}

We would like to extend our sincere thanks to the local people of Ghalegaon and to the interview and group discussion participants of this study for letting us know about themselves and their thoughts and experiences.

\section{References}

Acharya, B. P., \& Halpenny, E. A. (2013). Homestays as an alternative tourism product for sustainable community development: A case study of women-managed tourism product in rural Nepal. Tourism Planning \& Development, 10(4), 367-387.

Ahmad, J. A., Abdurahman, A. Z. A., Alik, J. K., Khedif, L. Y. B., \& Bohari, Z. (2014). Social entrepreneurship in ecotourism: An opportunity for fishing village of Sebuyau, Sarawak Borneo. Tourism, Leisure and Global Change, 1, TOC-38. 
Ahn, B., Lee, B., \& Shafer, C. S. (2002). Operationalizing sustainability in regional tourism planning: An application of the limits of acceptable change framework. Tourism Management, 23(1), 1-15.

Allen, C. R., \& Holling, C.(2010). Novelty, adaptive capacity, and resilience. Ecology and Society 15(3): 24.

Amir, A. F., Ghapar, A. A., Jamal, S. A., \& Ahmad, K. N. (2015). Sustainable tourism development: A study on community resilience for rural tourism in Malaysia. Procedia-Social and Behavioral Sciences, 168, 116-122.

Axelsson, R., Angelstam, P., Degerman, E., Teitelbaum, S., Andersson, K., Elbakidze, M., \& Drotz, M. K. (2013). Social and cultural sustainability: Criteria, indicators, verifier variables for measurement and maps for visualization to support planning. Ambio, 42(2), 215-228.

Azam, M., \& Sarker, T. (2011). Green tourism in the context of climate change towards sustainable economic development in the South Asian Region. Journal of Environmental Management \& Tourism, 1(3), 6-15.

Braun, V., \& Clarke, V. (2006). Using thematic analysis in psychology. Qualitative Research in Psychology, 3(2), 77-101.

Brown, F., \& Hall, D. (2008). Tourism and development in the global south: The issues. Third World Quarterly, 29(5), 839-849.

Byrd, E. T., Bosley, H. E., \& Dronberger, M. G. (2009). Comparisons of stakeholder perceptions of tourism impacts in rural eastern North Carolina. Tourism Management, 30(5), 693-703.

CBS. (2011). National population and housing census 2011 (village development committee/municipality): Lamjung. (No. Volume 06, NPHC2011). Kathmandu: Central Bureau of Statistics, Government of Nepal.

Charmaz, K. (2006). Constructing grounded theory: A practical guide through qualitative analysis. Thousand Oaks, CA: Sage.

Choi, H. C., \& Murray, I. (2010). Resident attitudes toward sustainable community tourism. Journal of Sustainable Tourism, 18(4), 575-594.

Choi, H. C., \& Sirakaya, E. (2006). Sustainability indicators for managing community tourism. Tourism Management, 27(6), 1274-1289.

Churchill, N. C., \& Lewis, V. L. (1983). The five stages of small business growth. Harvard Business Review, 61(3), 30-50.

Condon, L. (2004). Sustainability and small to medium sized enterprises: How to engage them. Australian Journal of Environmental Education, 20(1), 57-67. 
Creswell, J. W. (2007). Qualitative inquiry and research design: Choosing among five approaches (2nd ed.). Thousands Oak, CA: Sage.

Davoudi, S., Shaw, K., Haider, L. J., Quinlan, A. E., Peterson, G. D., Wilkinson, C., ... \& Davoudi, S. (2012). Resilience: A bridging concept or a dead end? "Reframing" resilience: challenges for planning theory and practice interacting traps: resilience assessment of a pasture management system in Northern Afghanistan urban resilience: what does it mean in planning practice? Resilience as a useful concept for climate change adaptation? The politics of resilience for planning: a cautionary note: edited by Simin Davoudi and Libby Porter. Planning Theory \& Practice, 13(2), 299-333.

Di Domenico, M., \& Lynch, P. (2007). Host/guest encounters in the commercial home. Leisure Studies, 26 (3), 321-338.

Farrell, B., \& Twining-Ward, L. (2005). Seven steps towards sustainability: Tourism in the context of new knowledge. Journal of Sustainable Tourism, 13(2), 109-122.

Folke, C., Carpenter, S. R., Walker, B., Scheffer, M., Chapin, T., \&Rockstrom, J.(2010). Resilience thinking: integrating resilience, adaptability and transformability. Ecology and Society, 15(4): 20.

Font, X., Garay, L., \& Jones, S.(2016). Sustainability motivations and practices in small tourism enterprises in European protected areas. Journal of Cleaner Production, 137, 1439-1448.

Franklin, A., Newton, J., \& McEntee, J. C. (2011). Moving beyond the alternative: Sustainable communities, rural resilience and the mainstreaming of local food. Local Environment, 16(8), 771-788.

George, E. W., Mair, H., \& Reid, D. G. (2009). Rural tourism development: Localism and cultural change. Buffalo: Channel View Publications.

Getz, D., Carlsen, J., \& Morrison, A. (2004). The family business in tourism and hospitality. Oxfordshire, UK: CABI.

Gibson, B., Hassan, S., Holtz, S., Tansey, J., Whitelaw, G. (2013). Sustainability assessment: Criteria and processes. NY: Earthscan, Routledge.

Gursoy, D., Jurowski, C., \& Uysal, M. (2002). Resident attitudes: A structural modeling approach. Annals of Tourism Research, 29(1), 79-105.

Hall, J., Matos, S., Sheehan, L., \& Silvestre, B. (2012). Entrepreneurship and innovation at the base of the pyramid: Arecipe for inclusive growth or social exclusion? Journal of Management Studies, 49(4), 785-812.

Harris, R. W. (2009). Tourism in Bario, Sarawak, Malaysia: A case study of pro-poor community-based tourism integrated into community development. Asia Pacific Journal of Tourism Research, 14(2), 125-135. 
Harrison, D. (1992). Tourism to less developed countries: The social consequences in tourism and the less developed countries. London: Bellhaven.

Harrison, D., \& Schipani, S. (2007). Lao tourism and poverty alleviation: Communitybased tourism and the private sector. Current Issues in Tourism, 10(2-3), 194230.

Holladay, P. J., and Powell, R. B. (2013). Resident perceptions of social-ecological resilience and the sustainability of community-based tourism development in the Commonwealth of Dominica. Journal of Sustainable Tourism, 21(8), 11881211.

Hopkins, D., \& Becken, S. (2014). Sociocultural Resilience and Tourism. In D. Hopkins \& S. Becken (Eds.) The Wiley Blackwell Companion to Tourism (pp. 490499). UK: John Wiley \& Sons, Ltd.

Jamal, T. B., \& Getz, D. (1995). Collaboration theory and community tourism planning. Annals of Tourism Research, 22(1), 186-204.

Kauppila, P., Saarinen, J., \& Leinonen, R. (2009). Sustainable tourism planning and regional development in peripheries: A Nordic view. Scandinavina Journal of Hospitality and Tourism, 9(4), 424-435.

Kimbu, A. N., \& Ngoasong, M. Z. (2016). Women as vectors of social entrepreneurship. Annals of Tourism Research, 60, 63-79.

Kontogeorgopoulos, N., Churyen, A., \& Duangsaeng, V. (2014). Success factors in community-based tourism in Thailand: The role of luck, external support, and local leadership. Tourism Planning \& Development, 11(1), 106-124.

Kuhlman, T., \& Farrington, J. (2010). What is sustainability? Sustainability, 2(11), 3436-3448.

Lew, A. A. (2014). Scale, change and resilience in community tourism planning. Tourism Geographies, 16(1), 14-22.

Liu, Z. (2003). Sustainable tourism development: A critique. Journal of Sustainable Tourism, 11(6), 459-475.

Lynch, P. (2005). The commerical home enterprise and host: A Unikted Kingdom perspective. International Journal of Hospitality, 24(4) 533-553.

Magis, K. (2010). Community resilience: An indicator of social sustainability. Society \& Natural Resources: An International Journal, 23(5), 401-416.

Man, T. W., Lau, T., \& Chan, K. F. (2002). The competitiveness of small and medium enterprises: A conceptualization with focus on entrepreneurial competencies. Journal of Business Venturing, 17(2), 123-142. 
Mbaiwa, J. E. (2011). Changes on traditional livelihood activities and lifestyles caused by tourism development in the Okavango Delta, Botswana. Tourism Management, 32(5), 1050-1060.

McIntosh, A., Lynch, P., \& Sweeney, M. (2011). My home is my castle: Defiance of the commercial home-stay host in tourism, Journal of Travel Research 50(5), 509-519.

Merriam, S. B. (2009). Qualitative research: A guide to design and implementation. revised and expanded from qualitative research and case study applications in education. San Francisco, CA: Jossey-Bass, A Wiley Imprint.

Moswete, N. N., Thapa, B., \& Child, B. (2012). Attitudes and opinions of local and national public sector stakeholders towards Kgalagadi Transfrontier Park, Botswana. International Journal of Sustainable Development \& World Ecology, 19(1), 67-80.

MoTCA. (2008). Paryatan Niti 2065 [Tourism Policy 2008]. Kathmandu: Ministry of Tourism and Civil Aviation.

MoTCA. (2009). Tourism vision 2020. Kathmandu: Ministry of Tourism and Civil Aviation.

MoTCA. (2010). Home-stay Sanchalan Karyabidhi, 2067 [Homestay Operations Procedures, 2010].Kathmandu: Ministry of Tourism and Civil Aviation.

Murillo, D., \& Lozano, J. M. (2006). SMEs and CSR: An approach to CSR in their own words. Journal of Business Ethics, 67(3), 227-240.

NRB. (2015). A Study on Dallagaon Homestay and Its Sustainability. A report of Nepalgunj Office, Banking Development and Research Unit: Nepal Rastra Bank.

Nunkoo, R., \& Gursoy, D. (2012). Residents' support for tourism: An identity perspective. Annals of Tourism Research, 39(1), 243-268.

Parker, S. (1999). Collaboration on tourism policy making: Environmental and commercial sustainability on Bonaire, NA. Journal of Sustainable Tourism, 7(3-4), 240-259.

Patton, M. Q. (2002). Qualitative research \& evaluation methods. Thousand Oaks, CA: Sage Publications.

Perdue, R. R., Long, P. T., \& Allen, L. (1990). Resident support for tourism development. Annals of tourism Research, 17(4), 586-599.

Peredo, A. M., \& Chrisman, J. J. (2006). Toward a theory of community-based enterprise. Academy of Management Review, 31(2), 309-328.

Regmi, K.D \& Walter, P.G. (2016) Conceptualising host learning in community-based ecotourism homestays. Journal of Ecotourism, 15(1), 51-63. 
Roberts, S., \& Tribe, J. (2008). Sustainability indicators for small tourism enterprises -- an exploratory perspective. Journal of Sustainable Tourism, 16(5), 575-594.

Ruiz-Ballesteros, E., \& Hernández-Ramírez, M. (2010). Tourism that empowers? Critique of Anthropology, 30(2), 201-229.

Russo, A., \& Tencati, A. (2009). Formal vs. informal CSR strategies: Evidence from Italian micro, small, medium-sized, and large firms. Journal of Business Ethics, 85(2), 339-353.

Saarinen, J. (2006). Traditions of sustainability in tourism studies. Annals of Tourism Research, 33(4), 1121-1140.

Scheyvens, R. (2011). Tourism and poverty. NY: Routledge.

Schmidt, H. (1989). What makes development? Development and Cooperation, 6,1926.

Scott, M., \& Bruce, R. (1987). Five stages of growth in small business. Long Range Planning, 20(3), 45-52.

Sebastian, L. M., \& Rajagopalan, P. (2009). Socio-cultural transformations through tourism: A comparison of residents' perspectives at two destinations in Kerala, India. Journal of Tourism \& Cultural Change, 7(1), 5-21.

Sharpley, R. (1994). Tourism, tourists and society. Huntingdon: ELM.

Simons, H. (2009). Case study research in practice. Los Angeles: Sage.

Simmons, D. (1994). Community participation in tourism planning. Tourism Management, 15(2), 98-108.

Sloan,P.,Legrand,W.,\&Simons-Kaufmann,C.(2014).A surveyof socialentrepreneurial community-based hospitality and tourism initiatives in developing economies: A new business approach for industry. Worldwide Hospitality and Tourism Themes, $6(1), 51-61$.

Smith, V. L. (1989). Hosts and guests: The anthropology of tourism. Philadelphia: University of Pennsylvania.

Stake, R. E. (2005). Qualitative case studies. In N. K. Denzin, \& Y. S. Lincoln (Eds.), The sage handbook of qualitative research (3rd ed., pp. 443-466). Thousands Oaks, CA: Sage.

Telfer, D. J. (2002). The evolution of tourism and development theory. In R. Sharpley, \& D. J. Telfer (Eds.), Tourism and development: Concepts and issues (pp. 35-80). Buffalo: Channel View Publications.

TheIndustrialEnterprises Act 2049.(2016). Retrieved from http://www.lawcommission. gov.np/page/2/?workflow_state=prevailing-laws-statutes-acts 
Thomas, R., Shaw, G., \& Page, S. J. (2011). Understanding small firms in tourism: A perspective on research trends and challenges. Tourism Management, 32(5), 963976.

Tosun, C. (1999). Towards a typology of community participation in the tourism development process. Anatolia, 10(2), 113-134.

UN. (1992). Agenda 21, the Rio Declaration on Environment and Development. United Nations Conference on Environment and Development (UNCED), June 1992. Rio de Janeiro: Brazil.

UN. (2012). The future we want-zero draft of the outcome document. Rio+20. United Nations Conference on Sustainable Development, June 2012. Rio de Janeiro: Brazil.

UNWTO. (2012). UNWTO tourism highlights (2012th ed.) United Nations World Tourism Organization.

Urry, J. (1991). The sociology of tourism. Progress in Tourism, Recreation and Hospitality Management 3, 48 \pm 57 .

Varghese, J., Krogman, N. T., Beckley, T. M., \& Nadeau, S. (2006). Critical analysis of the relationship between local ownership and community resiliency. Rural Sociology, 71(3), 505-527.

von der Weppen, J., \& Cochrane, J. (2012). Social enterprises in tourism: An exploratory study of operational models and success factors. Journal of Sustainable Tourism, 20(3), 497-511.

WCED. (1987). Our common future. NY: Oxford University Press.

Yang, L., Wall, G., \& Smith, S. L. J. (2008). Ethnic tourism development: Chinese government perspectives. Annals of Tourism Research, 35, 751-771.

Yin, R. K. (2014). Case study research: Design and methods (5th ed.).LA:Sage. 